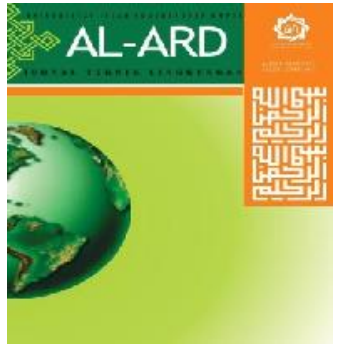

AL-ARD: JURNAL TEKNIK LINGKUNGAN

Vol.4 No.1 - September 2018(01-07)

\title{
KAJIAN AIR HUJAN MELALUI LUBANG RESAPAN BIOPORI (LRB) DI UIN SUNAN AMPEL SURABAYA
}

\author{
Luluk Martha' ${ }^{1}$, Abdul Hakim ${ }^{2}$, Rr Diah Nugraheni Setyowati ${ }^{3}$ \\ 1,2,3UIN Sunan Ampel, Surabaya, Indonesia \\ ${ }^{1}$ lulukmartha78@gmail.com \\ 2abdulhakim.hakim48@gmail.com \\ 32iahnugraheni@uinsby.ac.id
}

\begin{abstract}
Lack of green open space (RTH) can lead to flooding and even catastrophic flooding in the event of high rainfall intensity that falls in urban areas. Sunan Ampel State Islamic University Surabaya (UINSA) is one of the educational facilities in Surabaya City which is located in the flood prone area of Jemur Wonosari, Wonocolo. One of the technologies used to overcome inundation and flooding and to increase groundwater reserves is the Biopori Infiltration Hole (LRB). UINSA as one of the education facilities in Surabaya City can apply LRB technology to absorb rainwater so that it can reduce runoff of wasted rainwater into ditches to drainage systems. This study aims to determine the amount of LRB that can be applied in UINSA and the percentage of LRB in reducing drainage load. The method used is quantitative descriptive by conducting field survey of open land area, ground infiltration field test, soil type laboratory test and using secondary data daily rainfall. The results of the study showed that the number of LRB that can be applied at UINSA is 741 pieces in open spaces covering an area of $1481.84 \mathrm{~m}^{2}$ with a reduction in drainage load of $42.83 \%$. Keywords: rainwater, biopori infiltration hole, infiltration, drainage load reduction.
\end{abstract}

\begin{abstract}
Abstrak
Kurangnya Ruang Terbuka Hijau (RTH) dapat mengakibatkan genangan bahkan bencana banjir jika terjadi intensitas hujan tinggi yang turun di perkotaan. Universitas Islam Negeri Sunan Ampel Surabaya (UINSA) merupakan salah satu fasilitas pendidikan di Kota Surabaya yang terletak di wilayah rawan banjir Jemur Wonosari, Wonocolo. Salah satu teknologi yang digunakan untuk mengatasi genangan hingga banjir serta dapat menambah cadangan air tanah adalah Lubang Resapan Biopori (LRB). UINSA sebagai salah satu fasilitas pendidikan di Kota Surabaya dapat menerapkan teknologi LRB untuk meresapkan air hujan sehingga dapat mengurangi limpasan air hujan yang terbuang ke selokan hingga sistem drainase. Penelitian ini bertujuan untuk mengetahui jumlah LRB yang dapat diterapkan di UINSA dan besar prosentase LRB dalam mereduksi beban drainase. Metode yang digunakan adalah deskriptif kuantitatif dengan melakukan survei lapangan luas lahan terbuka, uji lapangan infiltrasi tanah, uji laboratorium jenis tanah dan menggunakan data sekunder curah hujan harian. Hasil penelitian diperoleh jumlah LRB yang dapat diterapkan di UINSA adalah 741 buah pada ruang terbuka seluas $1481,84 \mathrm{~m}^{2}$ dengan reduksi beban drainase sebesar $42,83 \%$.

Kata Kunci: air hujan, lubang resapan biopori, infiltrasi, reduksi beban drainase.
\end{abstract}

\section{PENDAHULUAN}

Kota Surabaya merupakan Ibukota Provinsi Jawa Timur. Universitas Islam Negeri Sunan Ampel Surabaya (UINSA) merupakan salah satu Universitas di Kota Surabaya dimana civitas akademika di UINSA tidak hanya berasal dari masyarakat Kota Surabaya, melainkan dari beberapa daerah di Indonesia. Bertambahnya penduduk berbanding lurus dengan peningkatan ekonomi warga yang menyebabkan semakin bertambahnya pemukiman. Padatnya bangunan di perkotaan dengan bertambahnya sarana prasarana pemukiman, jalan beraspal, jalan berpaving, mall, restaurant dan lain-lain mengakibatkan kurangnya Ruang Terbuka Hijau (RTH) serta kurangnya daerah resapan air.

Berdasarkan Undang-Undang Penataan Ruang No. 26 tahun 2007 Pasal 29 menetapkan bahwa kota harus menyediakan $20 \%$ dari luasnya sebagai RTH publik yang dikelola dan disediakan pemerintah serta 
minimal 10\% disediakan oleh pihak di swasta dan masyarakat. Sehingga secara keseluruhan, RTH yang disediakan kota minimal berjumlah $30 \%$ dari luas kota. Data Bappeko Surabaya tahun 2016, menyebutkan bahwa jumlah luasan RTH Kota Surabaya sebesar 6.853,46 Ha dengan prosentase luas RTH terhadap luas kota adalah 20,74 \%. Hal tersebut menunjukkan masih adanya kekurangan RTH sebesar 9,26\% (Puri, 2017).

Kurangnya RTH dapat mengakibatkan genangan bahkan bencana banjir jika terjadi intensitas hujan tinggi yang turun di perkotaan. Terhimpun dalam harian Sindo News pada hari Jumat, tanggal 24 November 2017telah terjadi banjir di Kota Surabaya, termasuk di Kelurahan Jemur Wonosari, Kecamatan Wonocolo yang terendam banjir cukup parah hingga masuk ke rumah-rumah warga. Jemur Wonosari merupakan wilayah di dekat kampus UINSA (Ulumuddin, 2017). Banjir yang melanda Kota Surabaya disebabkan karena kurangnya tatanan drainase dan ruang penampungan (serapan) air (Tito, 2016).

Banjir merupakan suatu bencana yang diakibatkan oleh aktivitas manusia diimbangi dengan tingginya curah hujan yang turun. Padahal, hujan merupakan suatu rahmat yang diturunkan oleh Allah SWT dan menjadi rezeki bagi makhluk hidup di dunia yang tertuang dalam kitab suci Al-Qur'an pada surah AlBaqoroh ayat 22 yang berbunyi:

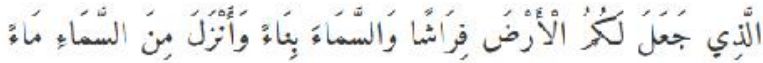

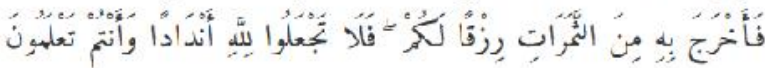

yang mempunyai arti "Dialah yang menjadikan bumi sebagai hamparan bagimu dan langit sebagai atap, dan Dia menurunkan air (hujan) dari langit, lalu Dia menghasilkan dengan hujan itu segala buah-buahan sebagai rezki untukmu; karena itu janganlah kamu Mengadakan sekutu-sekutu bagi Allah, padahal kamu mengetahui. Ialah segala sesuatu yang disembah di samping menyembah Allah seperti berhala-berhala, dewa-dewa, dan sebagainya". Hujan sebagai rezeki berbanding terbalik dengan bencana banjir yang kerap terjadi di Indonesia khususnya di UIN Sunan Ampel Surabaya, Kecamatan Wonocolo, Kota Surabaya. Hujan sudah selayaknya dimanfaatkan sehingga tidak lagi terjadi bencana banjir. Sehingga hujan akan menjadi rezeki bagi makhluk hidup tanpa menjadi bencana.
Berdasarkan siklus hidrologi, air hujan yang turun dan jatuh di permukaan tanah akan terdistribusi secara evapotranspirasi, infiltrasi/perkolasi dan melimpas kemudian mengalir ke badan air. Padatnya bangunan di perkotaan mengurangi luas lahan terbuka hijau mengakibatkan semakin besar debit limpasan air hujan dan semakin sedikit debit air yang mengalami proses infiltrasi ke dalam tanah (Damayanti, 2011). Salah satu cara untuk mengurangi air limpasan hujan sekaligus menanggulangi banjir adalah dengan meresapkan air ke dalam tanah dengan menggunakan teknologi Lubang Resapan Biopori (LRB). LRB dapat digunakan untuk menanggulangi banjir pada daerah yang sudah mulai berkurang daerah resapan airnya. Selain itu, LRB dapat membantu mengurangi kekeringan dan mengurangi beban sampah organik kota. Teknologi LRB dapat dibuat dengan mudah, biaya yang murah, tidak memerlukan lahan yang luas serta cepat dalam proses pembuatannya. LRB sangat sesuai bila diterapkan pada daerah yang mempunyai kepadatan bangunan dan pemukiman penduduk (Elsie, 2017).

UINSA sebagai salah satu fasilitas pendidikan di Kota Surabaya, tepatnya terletak di wilayah rawan banjir Jemur Wonosari, Wonocolo dapat menyumbang teknologi LRB untuk meresapkan air hujan sehingga dapat mengurangi limpasan air hujan yang terbuang ke drainase. Selain itu, LRB juga dapat berfungsi menambah cadangan air tanah di wilayah UINSA. Oleh karena itu, diperlukan studi mengenai resapan air hujan melalui LRB sebagai upaya mereduksi beban drainase di wilayah rawan banjir UINSA. Studi tersebut mencakup dari 2 (dua) tujuan penelitian, yakni merencanakan jumlah LRB yang dapat diterapkan serta besar pemanfaatan LRB dalam mereduksi beban drainase di UINSA.

\section{METODE PENELITIAN}

Metode yang digunakan dalam penelitian ini adalah Deskriptif Kuantitatif dengan menggunakan data primer dan data sekunder kemudian dihitung menggunakan beberapa rumus sehingga menghasilkan rencana jumlah biopori dan prosentase reduksi beban drainase. Lokasi penelitian berada di Universitas Islam Negeri Sunan Ampel Surabaya (UINSA). Lokasi penelitian ditunjukkan pada Gambar 1 berikut: 


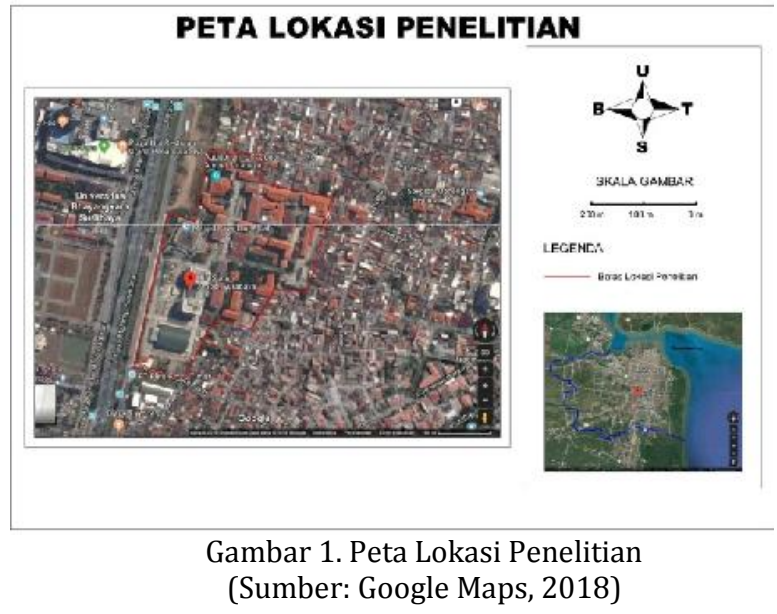

Penelitian menggunakan beberapa data primer dan data sekunder, yakni:

a. Data Primer

Data primer terdiri dari:

1. Data uji laboratorium jenis tanah. Jenis tanah menggunakan sampel tanah di lokasi penelitian. Uji laboratorium jenis tanah bekerja sama dengan pihak ketiga yakni Laboratorium Mekanika Tanah Jurusan Teknik Sipil ITS, Surabaya.

2. Data uji lapangan nilai infiltrasi tanah. Laju infiltrasi tanah di kampus UIN Sunan Ampel Surabaya didapatkan dengan mengukur langsung di lapangan dengan menggunakan metode infiltrasi tanah. Uji lapangan laju infiltrasi tanah digunakaan untuk mencari angka peresapan. Uji ini berfungsi untuk mengetahui daya resap tanah terhadap air. Uji lapangan infiltrasi menggunakan prinsip infiltrasi. Infiltrasi merupakan proses masuk/mengalirnya air ke dalam tanah secara gravitasi. Lokasi uji infiltrasi dilakukan pada 9 titik yang tersebar pada 3 wilayah berbeda, yakni 3 titik di belakang Masjid Ulul Albab, 3 titik di depan Fakultas Psikologi dan 3 titik di Samping Kopertais. Penentuan lokasi uji infiltrasi didasarkan pada metode purposive sampling. Metode purposive sampling digunakan dengan cara menentukan kriteria khusus terhadap sampel. Pengambilan sampel ditentukan yang dapat mewakili keadaan keseluruhan di lokasi penelitian (Priyono, 2016).

3. Data lahan terbuka hijau di UINSA.

Data lahan terbuka hijau di UINSA didapatkan dengan cara survei dan mengukur lahan secara langsung. b. Data Sekunder

Data sekunder terdiri dari:

1. Data siteplant kampus.

Data siteplant kampus didapatkan dari biro AUPK rektorat UINSA dan dengan menggunakan aplikasi Google Maps.

2. Data hujan harian dalam 10 tahun terakhir dari BMKG Maritim Perak Surabaya dan UPT PSDA Surabaya.

Data hujan harian dalam 10 tahun terakhir didapatkan dari BMKG Maritim Perak Surabaya dan UPT PSDA Surabaya. Data hujan harian menggunakan 3 (tiga) stasiun hujan terdekat dari lokasi penelitian, yakni stasiun hujan Kebonagung, stasiun hujan Gunungsari dan stasiun hujan Wonokromo.

Penelitian menggunakan beberapa prosedur penelitian yang terdiri dari:

1. Pengumpulan data primer dan data sekunder.

Pengumpulan data primer dan data sekunder dilakukan pada sumber-sumber data yang telah direncanakan.

2. Analisa hidrologi.

Analisa hidrologi dilakukan dengan menganalisa data curah hujan, analisa frekuensi curah hujan, analisa jenis sebaran, dan analisa keselarasan sebaran.

3. Menghitung intensitas hujan dan debit limpasan.

Intensitas hujan dihitung dengan menggunakan rumus intensitas hujan Mononobe (Sosrodarsono dan Takeda, 2003) berikut ini:

$\mathrm{I}=\frac{\mathrm{R}_{24}}{24}\left(\frac{24}{\mathrm{t}}\right)^{\frac{2}{3}}$

dimana:

I= Intensitas curah hujan (mm/jam)

$\mathrm{t}=$ Lamanya curah hujan (jam)

$\mathrm{R}_{24}=$ Curah hujan maksimum dalam 24 jam (mm)

Debit limpasan dihitung menggunakan rumus metode rasional (Triatmodjo, 2013) berikut ini:

$\mathrm{Q}=0,278 \times \mathrm{C} \times \mathrm{I} \times \mathrm{A}$

dimana:

$\mathrm{Q}=$ Debit puncak yang ditimbulkan oleh hujan dengan intensitas, durasi dan frekuensi tertentu (m3/detik)

$\mathrm{I}=$ Intensitas hujan (m/detik)

$\mathrm{A}=$ Luas daerah tangkapan (m2)

$\mathrm{C}=$ Koefisien aliran yang tergantung pada jenis permukaan lahan 
4. Menghitung laju infiltrasi.

Laju air yang terinfiltrasi ke tanah selama kurun waktu tertentu dapat dihitung dengan menggunakan data penurunan ketinggian air dalam kurun waktu tertentu.

5. Menghitung jumlah kebutuhan LRB di UINSA.

Jumlah LRB yang dibutuhkan dapat dihitung menggunakan rumus berdasarkan (Brata dan Nelistya, 2008) serta (Meliala, 2015) berikut ini:

Jumlah LRB $=\frac{I_{x} L_{\text {bidang }}}{\text { Laju }_{\text {Inf }}}$

$\mathrm{LRB}_{\text {maks }}=\frac{\mathrm{L}_{\mathrm{RTH}}}{\mathrm{L}_{\text {tanahideal }}} \times j$ umlah lubang ideal...(4)

dimana:

I= Intensitas hujan ( $\mathrm{mm} / \mathrm{jam})$

Lbidang $=$ Luas bidang kedap $\left(\mathrm{m}^{2}\right)$

Laju $_{\text {Inf }}=$ Laju infiltrasi (liter/jam)

$\mathrm{L}_{\mathrm{RTH}}=$ Luas Ruang Terbuka Hijau $\left(\mathrm{m}^{2}\right)$

$\mathrm{L}_{\text {tanahideal }}=$ Luas tanah ideal $\left(\mathrm{m}^{2}\right)$

6. Desain LRB di UINSA.

Desain LRB dibuat dengan menggunakan software Autocad 2010 dengan mengacu pada Peraturan Menteri Negara Lingkungan Hidup Nomor 12 Tahun 2009 dan (Brata dan Nelistya, 2008).

7. Analisa reduksi beban drainase di UINSA.

Analisa reduksi beban drainase dapat dihitung menggunakan rumus berdasarkan (Meliala, 2015) berikut:

$\%$ Reduksi $=\frac{\sum \text { Qserap LRB }}{\sum \text { Qwilayah }} \times 100 \%$

dimana:

$\Sigma Q_{\text {serap }} \mathrm{LRB}=$ Debit yang dapat diserap oleh LRB $\left(\mathrm{m}^{3} /\right.$ detik)

$\Sigma Q_{\text {wilayah }}=$ Debit hujan yang jatuh di seluruh wilayah penelitian $\left(\mathrm{m}^{3} /\right.$ detik).

\section{HASIL DAN PEMBAHASAN}

\section{Analisa Hidrologi}

Berdasarkan hasil perhitungan, curah hujan rencana pada periode 5 hingga 100 tahun menggunakan metode Log Pearson Tipe III disajikan pada Tabel 1 berikut:

Tabel 1. Curah Hujan Rencana Metode Log Pearson Tipe

\begin{tabular}{ccc} 
& & III \\
\hline No. & Periode & $\mathbf{X}_{\mathbf{t}}$ \\
\hline 1. & 2 & 510,104 \\
\hline 2. & 5 & 591,998 \\
\hline 3. & 10 & 639,872 \\
\hline 4. & 25 & 697,454 \\
\hline 5. & 50 & 729,313 \\
\hline 6. & 100 & 762,863 \\
\hline
\end{tabular}

(Sumber: Hasil Analisa, 2018)

Uji keselarasan data curah hujan menggunakan metode Smirnov-Kolmogorov p-ISSN: 2460-8815, e-ISSN: 2549-1652 dengan hasil perhitungan pada derajat signifikansi 0,05 (5\%) diperoleh hasil $D_{\text {maks }}$ sebesar 0,182 pada $(m=9)$ dan Do kritis sebesar 0,41 untuk jumlah data hujan sebanyak 10 tahun. Metode SmirnovKolmogorov memberikan hasil apabila Dmaks < Do kritis, sehingga metode sebaran yang diuji dapat diterima. Dengan hasil perhitungan yang diperoleh bahwa Dmaks $(0,182)<$ Do kritis $(0,41)$, sehingga metode sebaran yang diuji dapat diterima.

\section{Intensitas Hujan}

Intensitas hujan menggunakan rumus Mononobe mendapatkan hasil perhitungan yang ditunjukkan pada Tabel 2 berikut ini:

Tabel 2. Intensitas Curah Hujan

\begin{tabular}{ccccc}
\hline \multirow{2}{*}{ No. } & \multirow{2}{*}{ (jam) } & \multicolumn{3}{c}{ R24 (mm/jam) } \\
\cline { 3 - 5 } & & $\mathbf{R 2}$ & $\mathbf{R 5}$ & $\mathbf{R 1 0}$ \\
\hline & 1 & $\mathbf{5 1 0 , 1 0 4}$ & $\mathbf{5 9 1 , 1 0 4}$ & $\mathbf{6 3 9 , 8 7 2}$ \\
\hline 1. & 178,727 & 207,107 & 224,369 \\
\hline 2. & 2 & 112,331 & 130,168 & 140,907 \\
\hline 3. & 3 & 85,609 & 99,203 & 107,387 \\
\hline 4. & 4 & 70,601 & 81,811 & 88,561 \\
\hline 5. & 5 & 60,797 & 70,451 & 76,263 \\
\hline 6. & 6 & 53,806 & 62,349 & 67,494 \\
\hline
\end{tabular}

(Sumber: Hasil Analisa, 2018)

\section{Debit Limpasan}

Perhitungan debit limpasan menggunakan intensitas hujan durasi 2 jam pada kala ulang 5 tahun dengan pertimbangan menurut (Sanitya dan Burhanudin, 2012) dalam merencanakan jenis bangunan air seperti drainase saluran di sawah/permukiman digunakan kala ulang 5 hingga 10 tahun dan durasi hujan yang sering terjadi ada pada 1 hingga 6 jam. Koefisien aliran memakai koefisien (C) sebesar 0,6 dengan pertimbangan Kampus UINSA termasuk bangunan multi unit terpisah $(0,4-0,6)$ (Triatmodjo, 2013). Debit limpasan menggunakan rumus metode rasional mendapatkan hasil perhitungan yang ditunjukkan pada Tabel 3 berikut ini:

Tabel 3. Debit Limpasan

\begin{tabular}{|c|c|c|c|}
\hline No. & Lokasi & $\begin{array}{l}\text { Luas } \\
\left(\mathrm{m}^{2}\right)\end{array}$ & $\begin{array}{c}\text { Debit } \\
\text { Limpasan } \\
\left(\mathrm{m}^{3} / \mathrm{jam}\right)\end{array}$ \\
\hline 1. & Masjid & 311,45 & 6,762 \\
\hline 2. & Laboratorium & 67,25 & 1,460 \\
\hline 3. & Akademik Saintek & 104,18 & 2,262 \\
\hline 4. & Kopertais & 37,28 & 0,809 \\
\hline 5. & Fakultas Adab & 123,28 & 2,677 \\
\hline 6. & Fakultas Syariah & 84,87 & 1,843 \\
\hline 7. & Maqha & 42,84 & 0,930 \\
\hline 8. & Auditorium & 84,17 & 1,828 \\
\hline 9. & Gedung Transit & 55,10 & 1,196 \\
\hline
\end{tabular}




\begin{tabular}{|c|c|c|c|}
\hline No. & Lokasi & $\begin{array}{l}\text { Luas } \\
\left(\mathrm{m}^{2}\right)\end{array}$ & $\begin{array}{c}\text { Debit } \\
\text { Limpasan } \\
\left(\mathrm{m}^{3} / \text { jam }\right)\end{array}$ \\
\hline 10. & Fakultas Tarbiyah & 196,83 & 4,274 \\
\hline 11. & SAC & 22,75 & 0,494 \\
\hline 12. & Sport Center & 25,71 & 0,558 \\
\hline 13. & Twin Tower & 326,13 & 7,081 \\
\hline & Total UINSA & 1481,84 & 32,174 \\
\hline
\end{tabular}

(Sumber: Hasil Analisa, 2018)

\section{Jenis Tanah}

Hasil uji laboratorium pada sampel yang di lakukan di Laboratorium Mekanika Tanah dan Batuan, Jurusan Teknik Sipil, FTSP ITS, merupakan jenis tanah pasir berlempung berlanau, abu-abu terang yang tersusun atas 23, $80 \%$ kerikil; $44,30 \%$ pasir; $12,10 \%$ lanau; dan 19,80\% lempung. Dengan nilai koefisien permeabilitas tanah $(\mathrm{k})$ pada sampel sebesar 0,0246 .

\section{Laju Infiltrasi}

Laju infiltrasi berdasarkan hasil uji lapangan yang dilakukan di lokasi penelitian disajikan dalam Tabel 4 berikut ini:

Tabel 4. Laju Infiltrasi Sebelum dan Setelah Adanya LRB

\begin{tabular}{cccccc}
\hline & & \multicolumn{2}{c}{$\begin{array}{c}\text { Sebelum } \\
\text { Adanya LRB }\end{array}$} & \multicolumn{2}{c}{$\begin{array}{c}\text { Setelah Adanya } \\
\text { LRB* }\end{array}$} \\
\cline { 3 - 6 } No. Lokasi & $\begin{array}{c}\text { Penu- } \\
\text { runan } \\
\text { (cm) }\end{array}$ & $\begin{array}{c}\text { Laju } \\
\text { Infil- } \\
\text { trasi } \\
\text { (Liter/ } \\
\text { Jam) }\end{array}$ & $\begin{array}{c}\text { Penu- } \\
\text { runan } \\
\text { (cm) }\end{array}$ & $\begin{array}{c}\text { Laju } \\
\text { Infil- } \\
\text { trasi } \\
\text { (Liter } \\
\text { /Jam) }\end{array}$ \\
\hline 1. & $\begin{array}{c}\text { Lokasi } \\
1\end{array}$ & 33 & 6,47 & 60 & 18,55 \\
\hline 2. & $\begin{array}{c}\text { Lokasi } \\
2\end{array}$ & 20 & 4,08 & 59 & 12,04 \\
\hline 3. & $\begin{array}{c}\text { Lokasi } \\
3\end{array}$ & 26 & 5,30 & 60 & 18,55 \\
\hline
\end{tabular}

*uji infiltrasi air pada umur sampah 28 hari dan memakai sampah daun

(Sumber: Hasil Analisa, 2018)

Berdasarkan Tabel 4.21, terdapat perbedaan yang cukup signifikan antara laju resapan air/laju infiltrasi tanpa adanya biopori dengan setelah adanya biopori. Pada titik 1 yakni bertempat di belakang masjid Ulul Albab, laju infiltrasi sebelum adanya biopori adalah sebesar 6,47 liter/jam. Sedangkan setelah adanya biopori, laju infiltrasi bertambah menjadi 18,55 liter/jam. Penambahan laju infiltrasi tersebut adalah sebesar 186,71\%. Keadaan serupa juga terjadi di titik 2 yakni di depan fakultas psikologi dimana sebelum adanya biopori, laju infiltrasi adalah sebesar 4,08 liter/jam. Sedangkan setelah adanya biopori, laju infiltrasi bertambah menjadi 12,4 liter/jam dimana ada penambahan laju infiltrasi sebesar 195,10\%. Begitu pula pada titik 3 di samping kopertais. Sebelum adanya biopori, laju infiltrasi adalah sebesar 5,3 liter/jam. Sedangkan setelah adanya biopori, laju resapan bertambah menjadi 18,55 liter/jam. Adanya pertambahan laju infiltrasi karena adanya biopori, disebabkan adanya aktivitas mikroorganisme dari sampah daun di dalam biopori yang membantu kesuburan tanah, sehingga air yang masuk akan lebih cepat meresap ke dalam tanah. Laju infiltrasi yang semakin besar setelah adanya biopori diperkuat dengan ayat Al-Qur'an pada Surah Ar-Ra'd ayat 17, yang berbunyi:

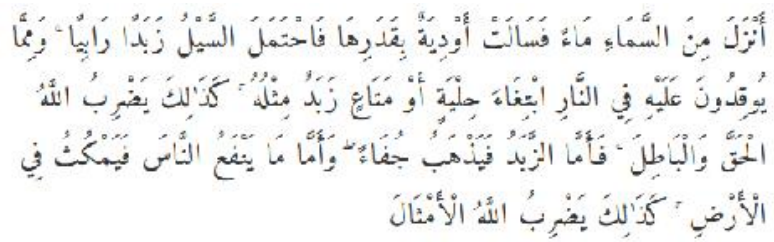

yang mempunyai arti "Allah telah menurunkan air (hujan) dari langit, Maka mengalirlah air di lembah-lembah menurut ukurannya, Maka arus itu membawa buih yang mengambang. dan dari apa (logam) yang mereka lebur dalam api untuk membuat perhiasan atau alat-alat, ada (pula) buihnya seperti buih arus itu. Demikianlah Allah membuat perumpamaan (bagi) yang benar dan yang bathil. Adapun buih itu, akan hilang sebagai sesuatu yang tak ada harganya; Adapun yang memberi manfaat kepada manusia, Maka ia tetap di bumi. Demikianlah Allah membuat perumpamaanperumpamaan". Tafsir Ibnu Katsir Jilid 4 menjelaskan bahwa Allah SWT telah menurunkan air hujan dari langit yang diserap oleh lembah-lembah menurut ukurannya; yang besar menyerap air lebih banyak dari yang kecil (Bahreisy, 1990). Berdasarkan tafsir tersebut, air dari langit (hujan) akan di serap oleh tanah menurut ukurannya. Biopori dapat membantu untuk meresapkan air hujan menjadi lebih cepat dan menyerap air lebih banyak. Karena tersedia lubang yang cukup besar untuk jalannya air hujan agar dapat mencapai dasar tanah daripada tanah yang tanpa diberikan biopori.

\section{Perencanaan LRB}

Berdasarkan hasil survei luas ruang terbuka yang berpotensi untuk pengaplikasian LRB dan hasil perhitungan, didapatkan jumlah LRB yang dapat diterapkan di UINSA yang ditunjukkan pada Tabel 5 berikut ini: 
Tabel 5. Perencanaan Jumlah LRB

\begin{tabular}{clcc}
\hline \multicolumn{1}{c}{ No. } & \multicolumn{1}{c}{ Lokasi } & $\begin{array}{c}\text { Luas } \\
\left(\mathbf{m}^{\mathbf{2}} \mathbf{)}\right.\end{array}$ & $\begin{array}{c}\text { Jumlah } \\
\text { LRB } \\
\text { (buah) }\end{array}$ \\
\hline 1. & Masjid & 311,45 & 156 \\
\hline 2. & Laboratorium & 67,25 & 34 \\
\hline 3. & Akademik Saintek & 104,18 & 52 \\
\hline 4. & Kopertais & 37,28 & 19 \\
\hline 5. & Fakultas Adab & 123,28 & 62 \\
\hline 6. & Fakultas Syariah & 84,87 & 42 \\
\hline 7. & Maqha & 42,84 & 21 \\
\hline 8. & Auditorium & 84,17 & 42 \\
\hline 9. & Gedung Transit & 55,10 & 28 \\
\hline 10. & Fakultas Tarbiyah & 196,83 & 98 \\
\hline 11. & SAC & 22,75 & 11 \\
\hline 12. & Sport Center & 25,71 & 13 \\
\hline 13. & Twin Tower & 326,13 & 163 \\
\hline & Total UINSA & 1481,84 & 741 \\
\hline
\end{tabular}

(Sumber: Hasil Analisa, 2018)

Total jumlah LRB yang dapat diterapkan pada ruang terbuka di UINSA dengan luas ruang terbuka sebesar 1481,84 m2 adalah sebanyak 741 buah biopori yang dapat diterapkan di seluruh ruang terbuka dengan tanah pada UINSA. Jumlah biopori yang dapat diterapkan tersebut dapat berdampak pada besar kecilnya reduksi beban drainase. Karena jumlah LRB yang diterapkan berbanding lurus dengan besarnya prosentase reduksi beban drainase.

Desain LRB direncanakan berdasarkan pada Peraturan Menteri Negara Lingkungan Hidup Nomor 12 Tahun 2009 dan (Brata dan Nelistya, 2008). Desain LRB ditunjukkan pada Gambar 2 berikut ini:

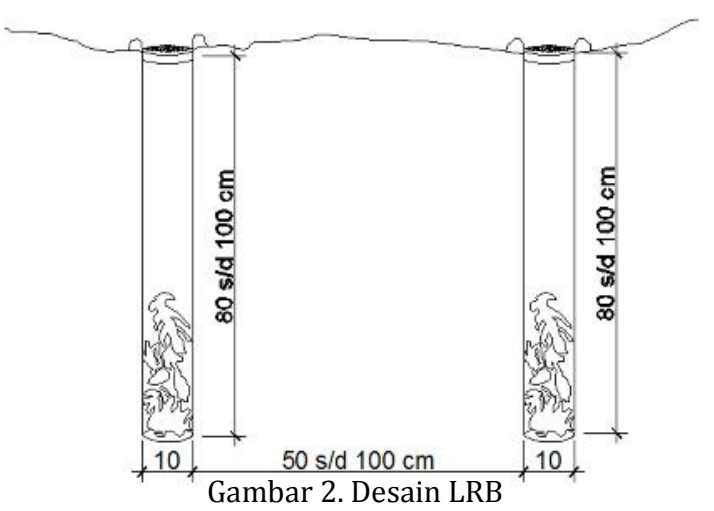

(Sumber: PERMENLH No. 12 Tahun 2009)

Perencanaan desain LRB berdasarkan Peraturan Menteri Negara Lingkungan Hidup Nomor 12 Tahun 2009 Tentang Pemanfaatan Air Hujan yakni:

a. LRB dapat dibuat dengan tinggi $60 \mathrm{~cm}$. Karena pada lokasi penelitian air tanah ada pada ketinggian kurang lebih $70 \mathrm{~cm}$ berdasarkan studi pendahuluan. b. LRB dapat dibuat dengan diameter $10 \mathrm{~cm}$ atau 4" ukuran pipa PVC dengan jarak antar lubang $50-100 \mathrm{~cm}$.

c. LRB dibuat dengan memasukkan sampah organik di dalamnya, dapat berupa sampah daun, sampah sayur, maupun sampah buah.

d. LRB dibuat dengan konstruksi pipa paralon pvc, tutup pipa berlubang, dan memberi semen pada sekeliling luar mulut lubang.

\section{Reduksi Beban Drainase Oleh LRB}

Reduksi beban drainase oleh LRB di lokasi penelitian dari hasil perhitungan ditunjukkan pada Tabel 6 berikut ini:

Tabel 6. Reduksi Beban Drainase Oleh LRB

\begin{tabular}{|c|c|c|c|c|}
\hline No. & Lokasi & $\begin{array}{l}\text { Luas } \\
\left(\mathrm{m}^{2}\right)\end{array}$ & $\begin{array}{c}\text { Jumlah } \\
\text { LRB } \\
\text { (buah) }\end{array}$ & $\begin{array}{c}\text { Reduksi } \\
\text { (\%) }\end{array}$ \\
\hline 1. & Masjid & 311,45 & 156 & 42,83 \\
\hline 2. & Laboratorium & 67,25 & 34 & 42,81 \\
\hline 3. & Akademik Saintek & 104,18 & 52 & 42,83 \\
\hline 4. & Kopertais & 37,28 & 19 & 42,89 \\
\hline 5. & Fakultas Adab & 123,28 & 62 & 42,85 \\
\hline 6. & Fakultas Syariah & 84,87 & 42 & 42,81 \\
\hline 7. & Maqha & 42,84 & 21 & 42,79 \\
\hline 8. & Auditorium & 84,17 & 42 & 42,83 \\
\hline 9. & Gedung Transit & 55,10 & 28 & 42,81 \\
\hline 10. & Fakultas Tarbiyah & 196,83 & 98 & 42,84 \\
\hline 11. & SAC & 22,75 & 11 & 42,91 \\
\hline 12. & Sport Center & 25,71 & 13 & 42,83 \\
\hline 13. & Twin Tower & 326,13 & 163 & 42,83 \\
\hline & Total UINSA & 1481,84 & 741 & 42,83 \\
\hline
\end{tabular}

(Sumber: Hasil Analisa, 2018)

Berdasarkan Tabel 6, dapat diketahui reduksi beban drainase di beberapa lokasi ruang terbuka di UINSA hampir sama yakni rata-rata sebesar $42,83 \%$. Reduksi beban drainase dipengaruhi oleh laju infiltrasi tanah di lokasi penelitian, jumlah LRB dan luas lahan terbuka yang tersedia. Berdasarkan hasil tersebut, membuktikan bahwa penerapan LRB dapat bermanfaat untuk mereduksi beban drainase. Reduksi beban drainase bila diterapkan LRB di UINSA, dapat memberikan beberapa manfaat dengan melihat kondisi eksisting di UINSA. Beberapa manfaat tersebut diantaranya, bila diterapkan LRB di UINSA, air hujan yang turun di lokasi dimana sebelumnya air hujan yang turun langsung masuk ke selokan-selokan hingga penuh dan meluber ke jalan, dengan adanya LRB, air hujan akan langsung masuk ke tanah melalui LRB sebelum masuk ke selokan. Hal tersebut dapat mengurangi air limpasan yang melimpas ke jalan, yang langsung masuk ke selokan hingga sistem drainase kampus dan sekitar kampus. Dengan adanya LRB juga dapat menambah 
cadangan air tanah dan juga dapat menyuburkan tanah karena adanya sampah organik di dalam LRB yang terdegradasi oleh fauna dan mikroorganisme tanah.

\section{KESIMPULAN}

Berdasarkan hasil dan pembahasan, dapat ditarik kesimpulan sebagai berikut:

1. Jumlah lubang resapan biopori (LRB) yang dapat diterapkan di Universitas Islam Negeri Sunan Ampel Surabaya adalah 741 buah pada lahan ruang terbuka seluas $1481,84 \mathrm{~m}^{2}$.

2. Besar pemanfaatan lubang resapan biopori (LRB) dalam mereduksi beban drainase di Universitas Islam Negeri Sunan Ampel Surabaya adalah sebesar $42,83 \%$.

\section{DAFTAR PUSTAKA}

Al-Qur'anul Karim.

Bahreisy, Salim \& Bahreisy Said. 1990. Terjemah Singkat Tafsir Ibnu Katsier Jilid 5. Bandung: Penerbit Sinar Baru Algensindo.

Bappeko Surabaya Tahun 2016.

Brata, R. \& A. Nelistya. 2008. Lubang Resapan Biopori. Jakarta: Penebar Swadaya.

Damayanti, W. Dwi. 2011. Sumur Resapan Air Hujan Sebagai Salah Satu Usaha Pencegahan Terjadinya Limpasan Pada Perumahan Graha Sejahtera 7, Boyolali. Tugas Akhir. Jurusan Teknik Sipil. Fakultas Teknik. Universitas Sebelas Maret Surakarta.

Elsie, I. Harahap, N. Herlina, Y. Badrun, N. Gesriantuti. 2017. Pembuatan Lubang Resapan Biopori Sebagai Alternatif Penanggulangan Banjir di Kelurahan Maharatu Kecamatan Marpoyan Damai Pekanbaru. Jurnal Untuk Mu Negeri. Vol. 1. No.2. ISSN : 2550-0198.

Google Maps, 2018.

Meliala, F. Rachmadin. 2015. Pemanfaatan Air Hujan melalui PAH dan Biopori Dalam Mereduksi Beban Drainase Pada Kawasan Pemukiman (Studi Kasus: Kawasan Banjir Pemukiman di Kelurahan Kedung Lumbu, Surakarta). Skripsi. Jurusan Teknik Sipil. Fakultas Teknik. Universitas Sebelas Maret Surakarta.

Peraturan Menteri Negara Lingkungan Hidup Nomor 12 Tahun 2009.

Priyono. 2016. Metode Penelitian
Kuantitatif. Sidoarjo: Zifatama Publishing.

Puri, H. Sekar. 2017. Perbandingan Pengelolaan Ruang Terbuka Hijau Kota Semarang dan Kota Surabaya Tahun 2010-2015. Departemen Politik dan Pemerintahan. Fakultas Ilmu Sosial dan Ilmu Politik. Universitas Diponegoro.

Sanitya, R. Sarah dan H. Bruhanudin. 2012. Penentuan Lokasi dan Jumlah Lubang Resapan Biopori di Kawasan DAS Cikapundung Bagian Tengah. Jurnal Perencanaan Wilayah dan Kota. Vol. 13. No. 1.

Sosrodarsono, Suyono \& Takeda. 2003. Hidrologi untuk Pengairan. Jakarta: Penerbit Pradnya Paramita.

Tito, Fahrizal. 2016. Pakar ITS: Banjir Surabaya Barat Akibat Minimnya Drainase.BeritaJatim.Tersedia:http://be ritajatim.com/peristiwa/260556/pakar its:_banjir_surabaya_barat_akibat mini mnya_drainase.html. Diakses pada tanggal 20 Maret 2018 Pukul 17.10 WIB.

Triatmodjo, Bambang. 2013. Hidrologi Terapan. Yogyakarta: Beta Offset.

Ulumuddin, Ihya. 2017. Warga Surabaya: Banjir Sepertin Ini kok Dibilang Genangan.SindoNews.Tersedia:https:// daerah.sindonews.com/read/1260327/ 23/warga-surabaya-banjir-seperti-inikok-dibilang-genangan-1511517656. Diakses pada tanggal 20 Maret 2018 Pukul 18.30 WIB.

Undang-Undang Penataan Ruang No. 26 Tahun 2007. 